\title{
ВЫЯВЛЕНИЕ АКТУАЛЬНЫХ ПРИНЦИПОВ ПОСТРОЕНИЯ ИНФОРМАЦИОННОЙ СИСТЕМЫ ХОЗЯЙСТВУЮЩЕГО СУБЪЕКТА
}

\author{
(c) 2019 Булыга Роман Петрович
}

доктор экономических наук, профессор, руководитель Департамента учета, анализа и аудита

Финансовый университет при Правительстве Российской Федерации, Россия, Москва

E-mail: RBulyga@fa.ru

Статья посвящена выявлению актуальных принципов построения информационной системы хозяйствующего субъекта, обеспечивающих контроль и анализ его деятельности, в том числе инновационной. Обосновывается необходимость расширения применяемых в настоящее время принципов.

Ключевые слова: информационная система, бухгалтерский учет, контроль и анализ деятельности

Информационные системы экономических субъектов, а также автоматизация и цифровизация систем бухгалтерского учета вышли на новую стадию развития и реализация новой модели бухгалтерского учета, которая обладает возможностями решения сложных задач обработки информации, требует обоснования новых принципов реализации данной системы. Особое место среди современных информационных систем занимают инновационные, включающие облачные технологии, внедрение независимых Web-приложений, открытые технологические платформы, а также интеллектуализация программных продуктов.

Информационные системы экономических субъектов поставлены во главу угла наиважнейших направлений стратегических документов, таких, как Концепция долгосрочного социальноэкономического развития Российской Федерации на период до 2020 г. и Стратегия развития информационного общества. Также в Указе Президента РФ от 7 мая 2018 года № 204 «О национальных целях и стратегических задачах развития Российской Федерации на период до 2024 года» [13] как приоритетное рассматривается развитие информационных систем на основе проектного управления. Также 24 декабря 2018 года был утвержден паспорт национальной программы «Цифровая экономика Российской Федерации». Данная программа включает пять федеральных проектов (приняты 28 мая 2019 г. протоколом № 9 заседания президиума Правительственной комиссии по цифровому развитию, использованию информационных технологий), направленных на совершенствование нормативной цифровой среды, кадровой поли- тики этой сферы, формированию и развитию информационной инфраструктуры и цифровых технологий, а также на цифровизацию системы государственного управления.

В РФ субъект хозяйствования обязан вести бухгалтерский учет в соответствии с Федеральным законом от 06.12.2011 № 402 «О бухгалтерском учете» [12], где отражены способы ведения учетной политики. Данным законом также предусмотрено, что субъект формирует эту политику самостоятельно. Правилами бухгалтерского учета $1 / 2008$ «Учетная политика организации» предусмотрена обработка информации, которая отнесена к способам ведения бухгалтерского учета. При этом технология обработки информации в нормативных актах не указана.

Информационная система субъекта экономической деятельности дает возможность информировать управленцев о развитии внутренней среды предприятия, а также формировать потоки входящей и исходящей информации.

Автоматизация системы управления субъекта хозяйствования базируется на автоматизации бухгалтерского учёта. Этому способствуют структурированность и четкий алгоритм постановки и реализации задач бухгалтерского учёта. Учетная сфера предполагает регистрацию информации обо всех хозяйственных операциях; а нормативы ГОСТ 34601-90 «Автоматизированные системы. Стадии создания», предусматривают возможность этапирования формирования автоматизированной системы.

Создание комплексной информационной автоматизации бухгалтерского учёта предусматривает решение взаимосвязанных задач.

Принципы построения системы бухгалтер- 
ского учета в современно ситуации тесно связаны с развитием информационных технологий, именно с учетом этого фактора требует их качественное расширение.

В модели бухгалтерского учета существует четыре основных элемента: методология; методика; организация процесса; технология. Под технологией понимается осуществляемый последовательно комплекс методов и приемов, нацеленных на достижение поставленной цели.

Российскими учеными [3; 4; 5; 7] сформирована целостная концепция информатизации процессов управления предприятием, включающая информационные системы учета, контроля, анализа хозяйственной деятельности. Также определено содержание информационной базы, которая является комплексом сведений об объекте управления, включающим нормативноправовую основу на носителе хранения, воспроизведения, корректировки и использования информации. Предусмотрено, что данная информация обрабатывается средствами вычислительной техники. Также в концепции определена особенность учетной информации. В первую очередь это ее цикличность, непрерывность обработки, и арифметические операции, при помощи которых осуществляются расчеты бухгал- терских операций.

Высокоперспективными векторами развития информационной системы субъекта хозяйствования является моделирование интеллектуальных технологий бухгалтерского учета, совершенствование принципиальной схемы работы гибких динамических компьютерных систем и модели построения адаптивной системы управленческого учета, а также на создание единого информационного пространства. Направления исследований по созданию единой информационной системы хозяйствующего субъекта представлены в таблице 1.

Информационная система хозяйствующего субъекта имеет несколько способов внесения в компьютерную базу данных, где осуществляется их автоматизированная обработка и формируются отчеты.

Возросшая важность технологии обработки информации, развитие профессиональных знаний и необходимость их формализации, алгоритмизация бухгалтерского учета выявили необходимость детализации информационной системы хозяйствующих субъектов, которая позволила бы обеспечить должный контроль и анализ его деятельности в системе бухгалтерского учета.

Таблица 1. Основные направления исследований единой информационной системы хозяйствующего субъекта

\begin{tabular}{|c|c|}
\hline $\begin{array}{c}\text { Направление исследования по формированию еди- } \\
\text { ного информационного пространства хозяйствующе- } \\
\text { го субъекта }\end{array}$ & Пояснения \\
\hline Пути интеграции различных программных средств & $\begin{array}{l}\text { Используются в учете интегрированные информа- } \\
\text { ционные системы - Enterprise Resource Planning, } \\
\text { ЕRP-системы, которые являются новым классом про- } \\
\text { дуктов. Наиболее распространены Web-технологии, } \\
\text { средство интеграции приложений - Web-сервисы. }\end{array}$ \\
\hline Замена закрытых систем на открытые & $\begin{array}{c}\text { Создание XBRL - «языка деловой отчетности», } \\
\text { открытого стандарта для представления финансо- } \\
\text { вой отчетности в электронном виде. Стандартизи- } \\
\text { рованный обмен информацией достигается путем } \\
\text { использования метаданных, определенных в перечне } \\
\text { таксономий. Таксономии содержат определения и } \\
\text { свойства отдельных элементов финансовых отчетов, } \\
\text { а также свойства взаимооношений между этими } \\
\text { элементами. }\end{array}$ \\
\hline $\begin{array}{c}\text { Направление исследования по формированию еди- } \\
\text { ного информационного пространства хозяйствующе- } \\
\text { го субъекта }\end{array}$ & Пояснения \\
\hline $\begin{array}{c}\text { Расширение технических возможностей передачи и } \\
\text { хранения данных }\end{array}$ & $\begin{array}{c}\text { Применение технологии сетей хранения данных } \\
\text { Storage Area Network (SAN). Перенос места хранения } \\
\text { информации за пределы хозяйствующих субъектов - } \\
\text { в «Облако», что позволит снизить затраты компании } \\
\text { на компьютерное сопровождение. }\end{array}$ \\
\hline
\end{tabular}

Источник: составлено по [3, 9]. 
Остановимся на принципе исключительной регистрации фактов ведения хозяйства при многократно формируемых отчетных регистрах. Он сложился на основе однократного ввода информации в автоматизированную систему, что позволяет формировать формы отчетности заданного формата и объема.

Инновационным направлением развития в сфере учета стала разработка информационных систем Business Intelligence. Они представляют собой системы анализа и оценивания информации, в которые входят сведения различного содержания из различных источников. Рассматриваемые системы имеют большие возможности использования как для оптимизации учета, так и для создания системы планирования деятельности субъекта хозяйствования, а также регулирования большими данными. Применение в системе бухгалтерского учета таких систем, безусловно, будет способствовать минимизации затрат экономических субъектов. Надо отметить, что заинтересованные игроки рынка для принятия соответствующих управленческих решений также нуждаются в получении верифицируемой и точной аналитической информации о деятельности хозяйствующего субъекта, которые может предоставить информационная система Business Intelligence.

Кроме несомненных плюсов, внедрение ин- новационных принципов построения информационных систем бухгалтерского учета, имеет ряд минусов, отраженных в таблице 2 .

Современная система автоматизированной обработки учетной информации опирается на общие и специфические принципы, раскрытые в таблице 3.

Рассмотрим основные принципы построения информационной системы хозяйствующего субъекта в соответствии с МСФО, отраженные в таблице 4.

Использование представленных принципов при построении информационной системы хозяйствующих субъектов и составлении отчетности приведет к улучшению как качественных характеристик отчета, так и организационного механизма разработки отчета.

В настоящее время, в целях совершенствования информационной системы хозяйствующего субъекта требуется дополнение принципов.

Рекомендуется расширить действующую систему бухгалтерского учета принципами, которые позволят построить качественную информационную систему хозяйствующего субъекта, в том числе инновационную. Среди предлагаемых принципов- принцип управления неопределенностью, открытостью, адаптивностью, комплексностью, прогнозируемости, саморазвития и самообучения.

\section{Таблица 2. Проблемы построения информационной системы хозяйствующего субъекта}

\begin{tabular}{|c|c|}
\hline Проблемы & Направления их решений \\
\hline $\begin{array}{l}\text { Общие проблемы - информационные, сервисные, } \\
\text { применения информации: } \\
\text { 1. несвоевременность дополнения информации; } \\
\text { 2. сложность удовлетворения индивидуальных за- } \\
\text { просов по получению информации; } \\
\text { 3. неполнота сведений по межотраслевым связям и } \\
\text { по взаимодействию со стейкхолдерами и обществен- } \\
\text { ностью } \\
\text { 4. недостаточная проработанность увязки источни- } \\
\text { ков отчетных данных; } \\
\text { 5. сложность осуществления электронных платежей. }\end{array}$ & $\begin{array}{l}\text { 1. Совершенствование системы сбора информации. } \\
\text { 2. Повышение ответственности за несвоевременную } \\
\text { сдачу отчетов. } \\
\text { 3. Развитие автоматизации службы по сбору и обра- } \\
\text { ботки данных. }\end{array}$ \\
\hline Обработка данных & $\begin{array}{l}\text { Необходимы дополнительные объемы данных, отра- } \\
\text { жающие специфику экономических процессов. }\end{array}$ \\
\hline $\begin{array}{l}\text { Взаимодействие «человек - машина»; рост требо- } \\
\text { ваний к компетенциям представителей професси- } \\
\text { онального сообщества, занимающегося анализом и } \\
\text { оценкой состояния субъекта хозяйственной деятель- } \\
\text { ности. }\end{array}$ & $\begin{array}{l}\text { Повышение квалификации представителей профес- } \\
\text { сионального сообщества. Использование инноваци- } \\
\text { онных специализированных программ, например, по } \\
\text { управлению цепочками поставок (SCM), управлению } \\
\text { производством (MRP), управлению взаимоотноше- } \\
\text { ниями с клиентами (CRM), бизнес-аналитике (BI), } \\
\text { инновационному проектированию (Project Expert); } \\
\text { а также применение панели индикаторов системы } \\
\text { сбалансированных показателей BPM/BSC (Business } \\
\text { Performance Management). }\end{array}$ \\
\hline
\end{tabular}

Источник: составлено на основе данных [2; 9]. 
Таблица 3. Принципы построение информационной системы субъектов хозяйствования

\begin{tabular}{|c|c|}
\hline \multicolumn{2}{|r|}{ Общие принципы } \\
\hline Принцип первого лица & Предусматривает право принятия управленческого решения и поряок ответственности \\
\hline системного подхода & $\begin{array}{l}\text { Базируется на осуществлении процесса проектирования информационных систем, } \\
\text { анализе и оценке объекта управления. Информация вводится однократно, а ее исполь- } \\
\text { зование является многократным. }\end{array}$ \\
\hline надежности & $\begin{array}{l}\text { Наличие качества долговременно хранения заданных свойств и осуществления задан- } \\
\text { ных функции }\end{array}$ \\
\hline непрерывного развития & $\begin{array}{l}\text { Предполагается наличие реальной возможности расширения деятельности субъекта } \\
\text { хозяйствования без проведения в обозримом будущем серьезных организационных } \\
\text { изменений и уменьшения масштабов деятельности. }\end{array}$ \\
\hline экономичности & $\begin{array}{l}\text { Базируется на основе эффективности (превышения выгоды над затратами) использо- } \\
\text { вания бухгалтерских информационных систем в системе управления предприятием. }\end{array}$ \\
\hline совместимости & $\begin{array}{l}\text { Основывается на том, что проектируемая бухгалтерская информационная система } \\
\text { будет учитывать целую группу условий функционирования субъекта хозяйствования: } \\
\text { организационную структуру предприятия, квалификацию и компетенцию специали- } \\
\text { стов, осуществляющих ведение бухгалтерского учета. }\end{array}$ \\
\hline \multicolumn{2}{|r|}{ Специфические принципы } \\
\hline $\begin{array}{l}\text { объединение различных } \\
\text { видов учета на основе } \\
\text { единой первичной } \\
\text { информации }\end{array}$ & $\begin{array}{l}\text { Взаимосвязь различных видов учета на основе единой первичной информации позво- } \\
\text { лит вывести информационные нужды управления на новый уровень, при этом слия- } \\
\text { ния видов учета - налогового, управленческого, финансового - не происходит, так как } \\
\text { каждый из них выполняет свои функции и решает свои задачи }\end{array}$ \\
\hline обратной связи & $\begin{array}{l}\text { Развитие устойчивых форм связи, позволяющих воздействовать на результаты бухгал- } \\
\text { терского учета и тем самым улучшать качественные характеристики информации и } \\
\text { отчетности. } \\
\text { Создание основы для применения автоматизации при осуществлении обработки } \\
\text { данных на всех этапах функционирования информационной системы хозяйствующего } \\
\text { субъекта }\end{array}$ \\
\hline
\end{tabular}

Источник: составлено на основе данных $[1 ; 2 ; 6 ; 8]$.

Таблица 4. Основные принципы построения информационной системы хозяйствующего субъекта в соответствии с МСФО

\begin{tabular}{|c|c|}
\hline принцип & описание \\
\hline $\begin{array}{l}\text { 1. Принцип начислений } \\
\text { (accruals concept/convention) }\end{array}$ & $\begin{array}{l}\text { Осуществление записи операций бухгалтерского учета в момент их соверше- } \\
\text { ния, и отнесения их к отчетному периоду, когда совершалась данная опера- } \\
\text { ция. }\end{array}$ \\
\hline $\begin{array}{l}\text { 1.1. принцип регистрации дохода } \\
\text { (realization concept) }\end{array}$ & $\begin{array}{l}\text { Отражение в отчетности дохода в том периоде, когда субъект хозяйствования } \\
\text { завершил все действия для его получения и данный доход считается зарабо- } \\
\text { танным (исключением является продажи в рассрочку). }\end{array}$ \\
\hline $\begin{array}{l}\text { 1.2. принцип соответствия } \\
\text { (matching concept) }\end{array}$ & $\begin{array}{l}\text { Отражение в отчетном периоде только тех расходов, которые привели к до- } \\
\text { ходам данного периода, поступления относятся к периоду продажи (или их } \\
\text { поставки и предоставления) }\end{array}$ \\
\hline $\begin{array}{l}\text { 2. Принцип функционирующего } \\
\text { предприятия (going concern). }\end{array}$ & $\begin{array}{l}\text { Предположение, что предприятие не имеет намерения сократить свою дея- } \\
\text { тельность или ликвидировать ее. }\end{array}$ \\
\hline $\begin{array}{l}\text { 3. Принцип двойной записи } \\
\text { (double entry). }\end{array}$ & $\begin{array}{l}\text { Выстраивается на основе того, что каждая операция отражается одновремен- } \\
\text { но и на одинаковую сумму по дебету одного и кредиту другого бухгалтерско- } \\
\text { го счета. При условии применения двойной записи возникает корреспонден- } \\
\text { ция счетов. }\end{array}$ \\
\hline $\begin{array}{l}\text { 4. Принцип единицы учета } \\
\text { (accounting entity). }\end{array}$ & $\begin{array}{l}\text { Предполагает, что предприятие, осуществляющее бухгалтерский учет и } \\
\text { представление отчетности, является самостоятельным хозяйствующим } \\
\text { субъектом }\end{array}$ \\
\hline $\begin{array}{l}\text { 5. Принцип периодичности } \\
\text { (periodicity) }\end{array}$ & $\begin{array}{l}\text { Предполагает, что финансовая отчетность должна предоставляться через } \\
\text { равные временные лаги. В РФ финансовый год совпадает с календарным } \\
\text { годом, в Англии - с } 1 \text { июля по } 31 \text { июня, в США разные штаты самостоятельно } \\
\text { выбирают временные промежутки отчетности . }\end{array}$ \\
\hline $\begin{array}{l}\text { 6. Принцип денежного измерителя } \\
\text { (monetary measurment) }\end{array}$ & $\begin{array}{l}\text { Базируется на том, что вся хозяйственная деятельность имеет единый де- } \\
\text { нежный измеритель. }\end{array}$ \\
\hline $\begin{array}{l}\text { 7. Принцип конфиденциальности } \\
\text { (confidence) }\end{array}$ & $\begin{array}{l}\text { Означает, что отчетная информация не наносит ущерба интересам субъекта } \\
\text { хозяйствования. Этот принцип в России не задекларирован }\end{array}$ \\
\hline
\end{tabular}

Источник: составлено на основе данных [10; 11]. 
Рассмотрим рекомендуемые принципы построение информационной системы хозяйствующего субъекта более подробно.

1. Принцип управления неопределенностью. Предполагает совершенствование системы управленческого учета в двух направлениях. Первое направление направлено на построение информационной основы выявления угроз и рисков деятельности субъектов хозяйствования, что позволит включать показатели и индикаторы рисков, которые формируются на основе учетных и управленческих данных. В результате создаваемая информационная система позволит получить комплексную оценку наличия угроз финансового развития предприятия, и система его менеджмента сможет соответствующим образом реагировать на них. Второе направление предполагает формирование системы управления рисками, в основе которой- информационное обеспечение отчетности, и нацеленность на дальнейшую оценку условий возникновения угроз и рисков.

2. Принцип открытости. Заключается в достоверности и верификации информации, применение удобного формата отчета, своевременности его публикации; изучении интересов разных групп игроков рынка и учет выявленных ожиданий к информации в отчетности

3. Принцип адаптивности. Наличие способности приспосабливаться к трансформации, сдвигам и преобразованиям информационной системы хозяйствующего субъекта с учетом внешних и внутренних требований

4. Принцип комплексности. Развитие информационной системы на основе комплексного подхода с обязательным обеспечением тесных связей всех подсистем и элементов деятельности хозяйствующего субъекта. Применение данного принципа позволит комплексно выявлять и решать проблемы функционирования механизма управления процессами инновационного развития в части экономического, социального, научно-технического, экологического, правового и других направлений

5. Принцип прогнозируемости. Базируется на обязательном учете вероятного характера реальных процессов развитии хозяйствующих субъектов с целью совершенствования системы бухгалтерского учета и достижения высоких результатов деятельности путем прогнозирования доходов и расходов

6. Принцип саморазвития и самообучения.
Характеризуется способностью к развитию хозяйствующего субъекта на основе построения его информационной системы в соответствии с требованиями экономики знаний и инноваций, что даст возможность обеспечить эластичность информации. Предполагает развитие большой сети коммуникаций всех заинтересованных сторон.

7. Принцип информационной безопасности. В его основе - обязательность создания и сохранения безопасности информации и учетной среды. Возможность использования «умных контрактов»

8. Принцип визуализации. Базируется на создании информативной и удобного для пользователя формы подачи отчетной информации

9. Принцип приоритетности инноваций. В его основе признание инноваций в качестве приоритетного конкурентного преимущества субъекта хозяйствования

10. Принцип восприимчивости к инновациям. Означает необходимость построения системы управления, восприимчивой к инновациям и способной их реализовывать

11. Принцип тесного взаимодействия с разными группами заинтересованных игроков рынка. Данный принцип предполагает построение отчетной информации с учетом ожиданий всех заинтересованных сторон

12. Принцип институционализации. Предполагает создание форм организации информационной системы хозяйствующего субъекта, направленных на формирование и развитие институциональных основ обеспечения инноваций.

13. Принцип системности. Заключается в формировании согласованного взаимодействия всех подсистем инновационной системы

14. Принцип капитализации инноваций В его основе трансформация ресурсов интеллектуального развития в интеллектуальный капитал, коммерциализация инноваций

15. Принцип синергии. Учитывающий, необходимость сотрудничества хозяйствующих субъектов и стейкхолдеров, и оказание управляющего воздействия на развитие инноваций, нацеленного на изменение эффективности деятельности за счет появления новых качеств информационной системы.

Среди преимуществ расширения принципов следует отметить возможность более эффективно осуществлять контроль и анализ деятельно- 
сти хозяйствующего субъекта; минимизировать инновационные риски; наладить согласованное взаимодействие всех подсистем инновационной системы хозяйствующего субъекта и внешней среды; учитывать вероятностные варианты развития хозяйствующих субъектов; рассматривать применение инноваций как приоритетное направление развития; обеспечить безопасность информационной среды учета, а также эластичность информации и более полно удовлетворить интересы в ней стейкхолдеров.

\section{Библиографический список}

1. Карпова Т.П. Направления развития бухгалтерского учета в цифровой экономике // Известия СанктПетербургского государственного экономического университета. - 2018. - № 3(111). - С. 52-57.

2. Легенчук С.Ф. Развитие принципов бухгалтерского учета в постиндустриальной экономике // Международный бухгалтерский учет. - 2012.- № 3 (201).- С. 21-27.

3. Малиновская Н.В., Малиновский М.Д. Международные тенденции развития интегрированной отчетности // Международный бухгалтерский учет. - 2018. - Т. 21, № 3.- С. 332-343. https://doi.org/10.24891/ ia. 21. 3.332

4. Мельник М.В. Модернизация учетно-контрольных и аналитических процессов в условиях цифровой экономики // Учет. Анализ. Аудит. - 2018. - № 3.- С. 129-130.

5. Рожнова О.В. Гармонизация учета, аудита и анализа в условиях цифровой экономики // Учет. Анализ. Аудит. - 2018. - № 3.-С. 16-23.

6. Ткач В.И. Становление и развитие системы цифрового учета и менеджмента // Аудиторские ведомости.2018. - № 1.- С. 70-75.

7. Хахонова Н.Н., Богатая И.Н. Будущее развития рынка аудиторско-консалтинговых услуг в условиях цифровой экономики // Аудиторские ведомости. - 2018. - № 2.- С. 13-24.

8. Языкова, С.В. Концептуальные основы внутреннего контроля // Экономика и предпринимательство.2017. - № 2.- С. 123-126.

9. Международный стандарт (ИО)// Международный совет по интегрированной отчетности (MCИO-IIRC). URL: http://integratedreporting.org/wp-content/uploads/2015/03/13-12-08-THE-INTERNATIONAL-IR-FRAMEWORK.docx_en-US_ru-RU.pdf

10. Сайт Фонд МСФО. URL: https://www.ifrs.org/about-us/who-we-are/

11. Ragulina J. V., Suglobov A.E., Melnik M.V. Transformation of the role of a man in the system of entrepreneurship in the process of digitalization of the Russian economy. Quality - Access to Success. - 2018. - № 19(S2). - P.171175.

12. Федеральный закон от 06.12.2011 № 402 «О бухгалтерском учете»

13. Указ Президента РФ от 7 мая 2018 года № 204 «О национальных целях и стратегических задачах развития Российской Федерации на период до 2024 года» 